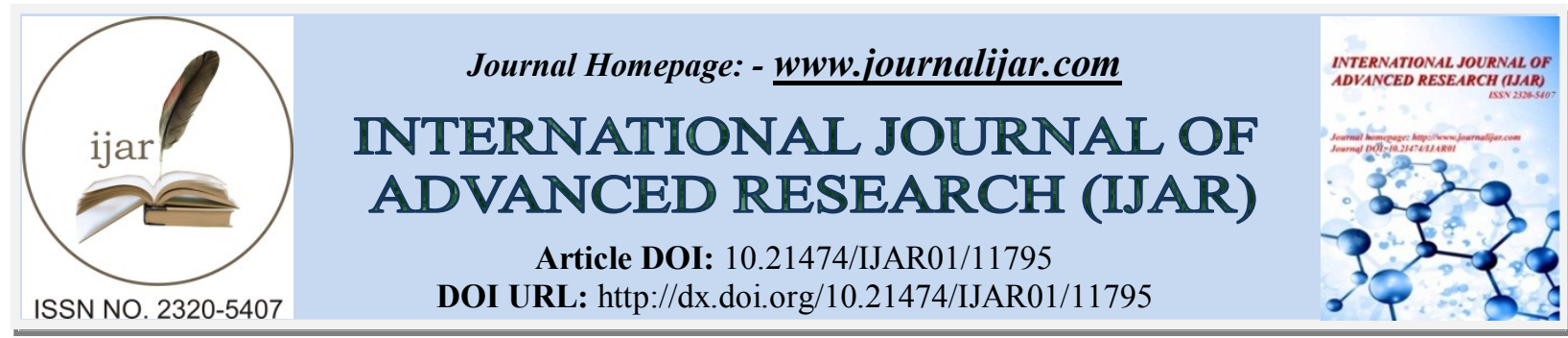

RESEARCH ARTICLE

\title{
STUDY OF VARIOUS TYPES OF TREATMENT MODALITIES IN CHILDREN WITH INTUSSUSCEPTION
}

\author{
Dr. Vikas Joshi, Dr. Prameshwar Lal, Dr. Praveen Mathur, Dr. Gurudutta Raipuria, Dr. Ajay Kumar and \\ Dr. Ravitej Singh Bal \\ Department of Pediatric Surgery, SMS Medical College, Jaipur, Rajasthan, India.
}

\section{Manuscript Info}

..........................

Manuscript History

Received: 26 July 2020

Final Accepted: 31 August 2020

Published: September 2020

Key words:-

Intussusception, Pneumatic Reduction, Ileo-Colic, Ileo-Ileal

\section{Abstract}

Background:Intussusception is a condition in which one part of gut enters into another part of gut known as telescoping. Ultrasonography of abdomen is highly specific and sensitive for diagnosis. Most of the ileo-ileal and fewer ileo-colic intussusceptions may reduce spontaneously. Ultrasound guided reduction is an alternative to surgery. If intussusception is not treated timely it may cause intestinal ischemia, gangrene, perforation peritonitis, shock and death.

Method:This is a hospital based prospective study including 96 patients over a period of 18 months. Detailed proforma was used, including name, age, sex, weight, presenting complaints, duration of complaints, abdominal sign \& symptoms, signs of the sepsis \& shock, peritonitis, perforation, USG finding, and type of surgery performed. The presence of the complications also noted.

Results:Maximum patients (63.5\%) of intussusception diagnosed were between 6 months to two years. Out of total 96 patients, 21 were treated by pneumatic reduction successfully. In 46 patient exploratory laparotomy and intra-operative reduction done, while in 29 children required resection anastomosis. Most common complaint was abdominal pain (100\%) followed by Excessive cry (92.7\%). Most common type of intussusception was Ileo-colic(88.5\%). Respiratory distress $(23.9 \%)$ followed by septicemia $(20.8 \%)$ was the most common complications.

Conclusions:Intussusception is a common surgical problem in childhood. Children of age 6 month to 2 years of age are affected most commonly. Ileo-colic is the most common type. Ultrasonography is diagnostic as well as therapeutic tool for intussusception. USG guided pneumatic reduction is a simple and good technique, if patient comes to hospital earlier. Early diagnosis of signs and symptoms may help clinician to take early interventions to save the gut as well life of the patient.

Copy Right, IJAR, 2020,. All rights reserved.

\section{Introduction:-}

Intussusception is a condition in which one part of gut enters into another part of gut known as telescoping ${ }^{1}$. Incident may vary from 1 to 4 per 1,000 live births and male to female ratio is $3: 1^{2}$. It is rarely found in children before age of 
2 month and peak is seen in between 5 to 7 month of age, then decline occurs ${ }^{3,4}$. Intussusception first described by barbette in Amsterdam in 1674 and sonographic features were described in $1977^{5,6}$. Ultrasonography of abdomen is highly specific and sensitive for diagnosis of intussusception. Classical triad of intussusception is vomiting, abdominal pain and red currant jelly stool ${ }^{7}$. This classical triad is seen only in one third of the patients. A palpable sausage shaped mass is found in right hypochondrium in $60 \%$ of the cases. In x-ray "target sign" and "meniscus sign" may be seen in 25 to $50 \%$ of the cases, so usefulness of x-ray in diagnosis of intussusception is limited ${ }^{8}$. But it is valuable in diagnosis of intestinal perforation and pneumoperitoneum associated with intussusception. Contrast enema had also been also used to diagnose intussusception in the past. Ultrasound has replaced contrast enema to diagnose intussusception as it is more convenient and safe for the patients. It is also used to find out the lead points $^{10}$.

Most of the ileo-ileal and fewer ileo-colic intussusceptions may reduce spontaneously. In hydrostatic reduction pressure is given on apex of intussusceptum in colon till its complete reduction ${ }^{11}$. Ultrasound guided reduction is easier than fluoroscopy guided reduction ${ }^{12}$. Ultrasound guided reduction is an alternative to surgery and also there is no risk of radiation exposure as seen in fluoroscopy ${ }^{13}$. If intussusception is not treated timely it may cause intestinal ischemia, gangrene, perforation peritonitis, shock and death. Death is more commonly seen in developing countries due to delay in diagnosis ${ }^{14}$.

\section{Methods:-}

This was a hospital based prospective study in the department of pediatric surgery, SMS Medical College, Jaipur, Rajasthan.

\section{Inclusion criteria:-}

Ultrasound diagnosed cases of intussusception with age between 2 months to 12 years.

\section{Exclusion criteria:-}

1. All transient intussusception patients.

2. Patients of age more than 12 years.

A total of 96 patients were included in the study from September 2018 to February 2020. Parents were explained for the need for the study and written and informed consent was taken. Detailed proforma was used, including name, age, sex, weight, presenting complaints, duration of complaints, abdominal sign \& symptoms, signs of the sepsis \& shock, peritonitis, perforation, USG finding, and type of surgery performed. The presence of the complications also noted.

\section{Results:-}

All 96 children were diagnosed by ultrasound of abdomen. The mean age of presentation was 17 months. Maximum patients $(63.5 \%)$ of intussusception diagnosed were between 6 months to two years. Below six month patients were $13.5 \%$ (13) and above 2 year patients were $22.9 \%$ (22).

Table 1:- Age wise distribution of patients $(\mathrm{n}=96)$.

\begin{tabular}{|c|c|c|c|}
\hline Age & No. of Patients & Percentage \\
\hline$<6$ months & 13 & $13.5 \%$ \\
\hline 6 months to 2 years & & 61 & $63.5 \%$ \\
\hline$>$ 2 years & 22 & $22.9 \%$ \\
\hline
\end{tabular}




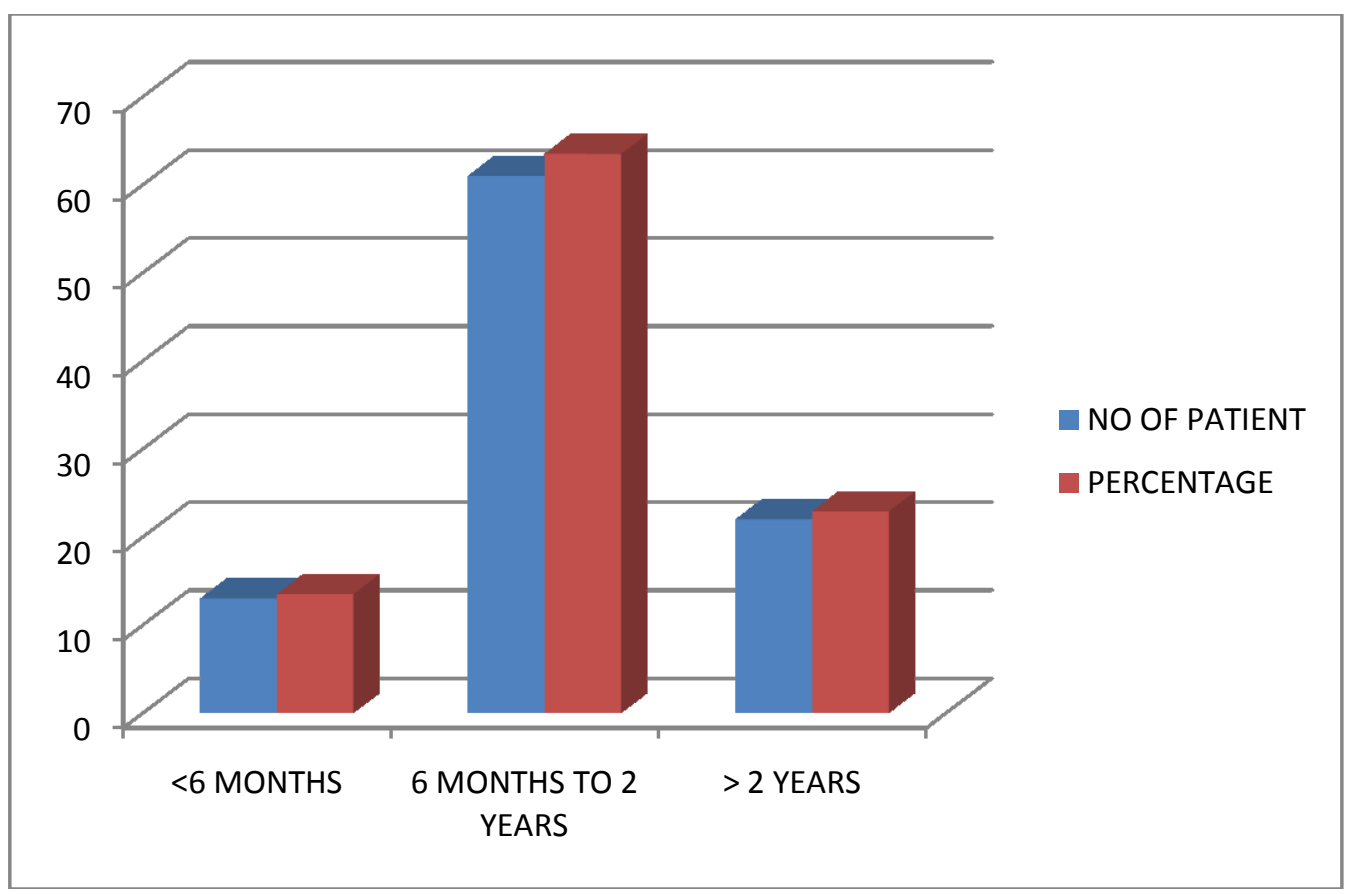

Figure 1:- Age wise distribution of patients $(\mathrm{n}=96)$.

Table 2:- Various treatment modalities for intussusception $(\mathrm{n}=96)$.

\begin{tabular}{|c|c|c|}
\hline Treatment Modality & No. Of Patients & Percentage \\
\hline pneumatic reduction & 21 & $21.80 \%$ \\
\hline Intra operative manual reduction & 46 & $47.90 \%$ \\
\hline resection anastomosis & 29 & $30.20 \%$ \\
\hline
\end{tabular}

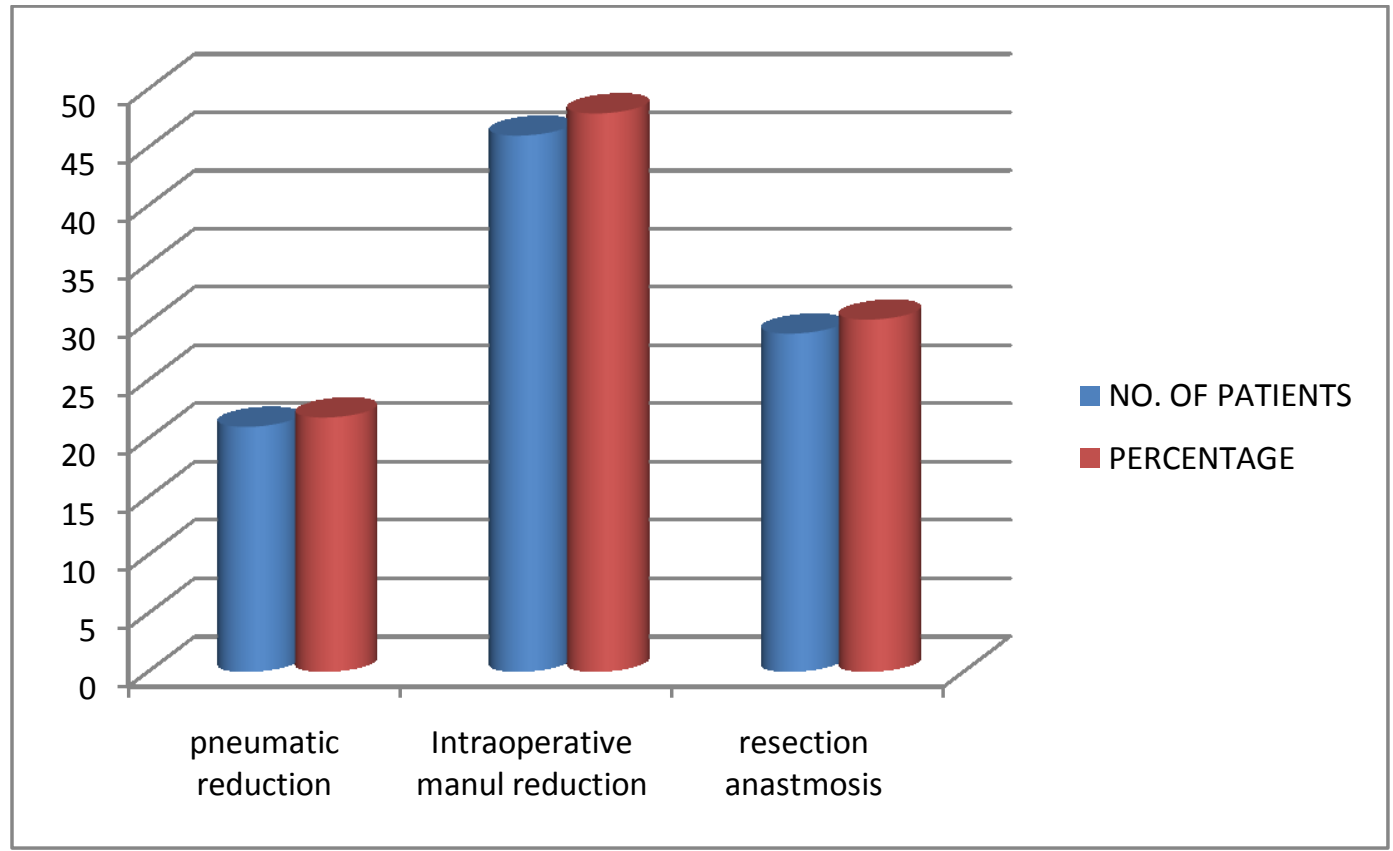

Figure 2:- Various treatment modalities for intussusception $(\mathrm{n}=96)$.

Out of total 96 patients, $21(21.8 \%)$ were treated by pneumatic reduction successfully. In remaining 75 patients exploratory laparotomy was done and intra-operative reduction was sufficient in 46 children (47.9\%) but in 29 children $(30.2 \%)$ resection anastomosis was done. 
Table 3:- Percentage distribution based on presenting complaints $(\mathrm{n}=52)$.

\begin{tabular}{|l|l|l|}
\hline Presenting Complaint & No. Of Patients & Percentage \\
\hline Pain abdomen & 96 & $100 \%$ \\
\hline Excessive cry & 89 & $92.70 \%$ \\
\hline Vomiting & 76 & $79.10 \%$ \\
\hline Abdominal mass & 69 & $71.80 \%$ \\
\hline Abdominal distention & 64 & $66.66 \%$ \\
\hline Bleeding PR & 38 & $39.50 \%$ \\
\hline
\end{tabular}

Most common complaint was abdominal pain which was present in all $96(100 \%)$ patients. Excessive cry was second most common symptom present in $92.70 \%$ patients, and vomiting was also presenting complaint in 76 (79.1\%) patients. Abdominal mass and abdominal distention were observed in $69(71.8 \%)$ and $64(66.66 \%)$ patients respectively. Red recurrent jelly in stool or history of bleeding per rectal is however, very important finding but it was seen in only in $38(39.50 \%)$ patients. Out of them, in 9 children vomiting was bilious (9.3\%). 89 children $(92.7 \%$ ) had excessive cry. 38 children (39.5\%) presented with blood in stool. All children complaint of pain abdomen out of which 37 patients presented with gradual pain abdomen $(38.5 \%)$ and 59 patients had sudden onset $(61.4 \%)$. In 69 patients $(71.8 \%)$ abdominal mass was present. Abdominal distention was seen in 64 patients $(66.66 \%)$.

Table 4:- Percentage distribution based on the type of intussusceptions.

\begin{tabular}{|c|c|c|}
\hline Types Of Intussusception & No. Of Patients & Percentage \\
\hline Ileo-colic & 85 & $88.54 \%$ \\
\hline Ileo-colo- colic & 4 & $4.16 \%$ \\
\hline Ileo-ileal & 3 & $3.10 \%$ \\
\hline Ileo-ileo-colic & 3 & $3 \%$ \\
\hline Colo-colic & 1 & $1.04 \%$ \\
\hline
\end{tabular}

Out of 96 children, 85 (88.54\%) had ileo-colic type of intussusception, suggesting that it is the most common type of intussusception in children. Other type of intussusception were ileo-colo-colic, ileo-ileal, ileo-ileo-colic and colocolic which were present in $4(4.16 \%), 3(3.1 \%), 3(3.1 \%)$ and $1(1.04 \%)$ patients respectively.

Table 5:- Percentage distribution based on complication.

\begin{tabular}{|c|c|c|}
\hline Complication & No. Of patients & Percentage \\
\hline Respiratory distress & 23 & $23.90 \%$ \\
\hline Signs of sepsis and peritonitis & 20 & $20.83 \%$ \\
\hline Recurrence & 2 & $2.08 \%$ \\
\hline Leak of anastomosis & 1 & $1 \%$ \\
\hline
\end{tabular}

Respiratory distress and signs of sepsis \& peritonitis were the most common complications among in our patients and they seen in $23(23.9 \%)$ and 20 (20.83\%) patients respectively. Two patients developed recurrence (2.08\%), one patient developed leak of anastomosis post operatively $(1.04 \%)$.

\section{Discussion:-}

Intussusception is the most common surgical emergency in children less than two years of age group ${ }^{16}$. In present study we described all clinical conditions and type of intussusception. In our study youngest age of presentation was 2 months and oldest was 11 years 11 months. The most common symptom noted was abdominal pain, which was observed in all the patients. Out of 96 patients $21(21.8 \%)$ underwent pneumatic reduction successfully. In remaining patients laparotomy was performed and $46(47.9 \%)$ patients underwent manual reduction while 29 (30.2\%) patients required resection anastomosis due to pregangrenous changes in gut. A total $20(20.83 \%)$ patients developed symptoms of peritonitis and sepsis all were managed successfully and no death occurred during our study. In one patient who required exploratory laparotomy with resection and anastomosis developed leak on post operative day 4. A second look operation performed and stoma surgery done, patient recovered well and post operative duration was uneventful, so discharged after recovery. Eleven patients required stoma during surgery and 19 patients developed paralytic ileus postoperatively. 
Our present study describes all clinical conditions and type of intussusception. All patients were diagnosed by ultrasound. Most intussusception develops before 2 years of age. In our study 61 children (63.5\%) were between the age of 6 months to 2 years, which is consistent with the literature showing $80 \%$ cases occurs in less than two years of age. In our study 13 children were less than 6 months and 22 children were more than two years. Some publications show that $50 \%$ of cases may occur in second year of life $^{16}$.

In a study done by Yacin S et al. in intussusception patients, $67 \%$ of the cases were under one year of age ${ }^{17}$. Weihmiller et al. found median age to be 21.1 months in his study and they observed male gender is a significant predictor of intussusception ${ }^{18}$. In our study median was 17 months. Out of 96 children $62(62.5 \%)$ were male showing male predominance has been found by several researchers worldwide. Male to female ratio in our study was $1.8: 1$. Weihmiller et al. found $61 \%$ of male and male to female ratio was $1.58: 1$ in their study. Bajaj et al also found male predominance with $60 \%$ male in their study ${ }^{19}$. Khan et al found male to female ratio $3.4: 1$ in his study ${ }^{20}$. Another study by Kumar et al they also found $64 \%$ male in his study group ${ }^{21}$.

In our study most common symptom was abdominal pain followed by excessive cry then vomiting and bleeding per rectum. A total of $76(79.16 \%)$ children presented with vomiting from these 9 patients were having bilious vomiting. Kumar k et al found commonest symptom was colicky abdominal pain. Abdominal pain was present in $78.08 \%$ of the patient in study of khan $\mathrm{j}$ et al and 52- $85 \%$ of the patients in studies done by Julie EB et al. hutchinson et al, Ein $\mathrm{SJ}$ et al and mansur $\mathrm{SH}$ et al have reported that vomiting, abdominal distension, bleeding per rectum and palpable abdominal mass are the commonest presenting features of intussusception ${ }^{22,23,24,25}$. Loss of acquired immunity from Mother after 6 months and early weaning of the mother's milk is associated with idiopathic ileocolic intussusception ${ }^{26}$.

Usually $90 \%$ of the intussusception cases are idiopathic but lead point may be present in 2 to $10 \%$ of the cases Pathological apex of intussusceptum is noticed in less than $5 \%$ of the cases. Lead point may be meckel's diverticulum, polyp, neurofibroma, duplication cyst, inverted appendix stump, leiomyoma, hamartoma, ectopic pancreatic tissue, anastomotic suture lines and entrostomy tubes, post-transplant lymphoproliferative disease, hemangioma or malignant conditions such as lymphoma, kaposi sarcoma. Lead point is most commonly found in older children ${ }^{10}$. We found lead point in $18(18.75 \%)$ patients. Respiratory tract infection was present in 14 patients $(14.98 \%)$ in our study. Correlation with respiratory tract infection has been noted in other studies also. Gastrointestinal tract infection was also present in 12 patients $(12.5 \%)$ within the duration of two weeks. In acute gastroenteritis hyperperistalsis and mesenteric lymphadenopathy are seen which is associated with idiopathic ileocolic intussusception. In children less than 1 years of age who received rotavirus vaccine may present intussusception within two weeks of immunization ${ }^{27-28 .}$ In our study none of the patient received any rotavirus vaccine. Most of the patients were seen in February followed by September. Seasonal incidence was noticed in other studies also. Peak is seen in the winter. Most common type of intussusception was ileocolic which is comparable to most of the other studies. In our study 85 (88.54\%) patients presented with ileocolic type of intussusception. Four children had ileo-colo-colic intussusception (4.16\%), three patients had ileo-ileal and ileo-ileo-colic intussusception each (3.1\%). 1 patient (1.04\%) had colo-colic intussusception.

USG screening has increased the therapeutic efficiency in the treatment of intussusception as it causes no radiation exposure in children. It has a sensitivity of approximately $98-100 \%$ and specificity of approximately $98 \%$ in diagnostic intussusception. Pneumatic reduction is associated with minimum complications as compared to contrast hydrostatic methods as it causes less radiation exposure. In our study $21(21.8 \%)$ patients underwent pneumatic reduction by ultrasound guidance successfully. In patients with prolonged history of intussusception with signs of shock, peritonitis and pneumoperitoneum, pneumatic reduction should not be attempted. Surgical procedure is indicated in the presence of shock and necrosis, perforation peritonitis, and in patients with multiple recurrence with lead points. delay in the diagnosis determines the procedure to be done for the reduction ${ }^{29}$. All patients of the study population required surgery in study bajaj et $\mathrm{al}^{19}$. Ileo ileal intussusception is common with henoch schonlein purpura and usually resolves without the need for any specific treatment. If manual reduction is impossible, resection of the intussusception is necessary with end-to-end anastomosis. In our study 29 patients (30.2\%) underwent resection anastomosis. Recurrence was seen in $1(2.17 \%)$, patient of manual reduction and in 1 patients $(4.76 \%)$ of pneumatic reduction. In a study by Daneman et al. recurrence rate after pneumatic reduction was $10 \%$ and nil after surgical resection ${ }^{30}$. Recurrence rate was $10.3 \%$ in study of Bajaj et al. ${ }^{19}$ recurrence rate and was $2.2 \%$ in study of yalcin $\mathrm{S}^{17}$. There was no recurrence in study of Krishna kumar et $\mathrm{al}^{21}$. 
In our study $23(23.9 \%)$ patients developed respiratory distress, while signs of sepsis and peritonitis seen in 20 patients $(20.83 \%)$. Two (2.08\%) patients developed recurrence and $1(1.04 \%)$ patient developed leak of anastomosis post operatively.

\section{Conclusion:-}

Intussusception is a common surgical problem in childhood. Children of age 6 month to 2 years of age are affected most commonly. Abdominal pain, vomiting, excessive cry and bleeding per rectum were other common symptoms. Ileo-colic type of intussusception is the most common in children. Ultrasonography is diagnostic as well as therapeutic tool for intussusception. USG guided pneumatic reduction was found to be a simple and good technique if patient comes to hospital earlier. USG also confirm the pneumatic reduction along with the diagnosis of intussusception and the technique is cost effective, easy, without radiation hazards and less hospital stay. If intussusceptions if left untreated may result in fatal outcome. Early diagnosis of signs and symptoms may help clinician to take early interventions to save the gut as well life of the patient.

\section{References:-}

1 Bines JE, Ivanoff B, Justice F, et al. Clinical case definition for the diagnosis of acute intussusception. J Pediatr Gastroenterol Nutr. 2004; 39(5):511-8.

2 Kleigman, Behrman, Jenson. Intussusception. Nelson text Book of Pediatrics, 20th ed' Philadelphia WB Saunders. 2016; 2:1812-1813.

3 Vanessa MW, Intussusception. In Lewis S, Arnold GC, eds. Rob and Smith's Operative Surgery Pediatric Surgery, 4th ed, London. Chapman and Hall Medical; 1994; 396-397.

4 Bines J, Ivanoff B. Acute Intussusception in Infants and Children. Geneva, Switzerland: World Health Organization; 2002.

5 Irish MS. Intussusception: Surgical Perspective. Emedicine. 2006.

6 Mensah Y, Etwire V. Ultrasound guided Hydrostatic Reduction of Intussusceptionin children at Korle Bu Teaching Hospital: An Initial Experience Ghana Med J. 2011;45(3):128-31.

7 Lehnert T, Sorge I, Till H. Intussusception in children - clinical presentation, diagnosis and management. Int J Colorectal Dis. 2009; 24(10):1187-92.

8 Smith DS, Bonadio WA, Losek JD, et al. The role of abdominal x-rays in the diagnosis and management of intussusception. Pediatr Emerg Care. 1992;8(6):325-7.

9 Ugwu BT, Legbo JN, Dakum NK, Yiltok SJ, Mbah N, Uba FA. Childhood intussusception: a 9-year review. Ann Trop Pediatr. 2000; 20(2):131-5.

10 Justice FA, Auldist AW, Bines JE. Intussusception: trends in clinical presentation and man-agement J Gastroenterol Hepatol. 2006; 21(5):842-6.

11 Navarro O, Dugougeat F, Kornecki A, Shuckett B, Alton DJ, Daneman A. The impact of imaging in the management of intussusception owing to pathologic lead points in children: a review of 43 cases. Pediatr Radiol. 2000;30(9):594-603.

12 Bhisitkul DM, Listernick R, Shkolnik A. Clinical application of ultrasonography in the diagnosis of intussusception. J Pediatr. 1992; 121(2):182-6.

13 Gonzalez-Spinola J, Del Pozo G, Tejedor D. Intussusception: the accuracy of ultrasound- guided saline enema and the usefulness of a delayed attempt at reduction. J Pediatr Surg 1999; 34(6):1016-20.

14 Fischer TK, Bihrmann K, Perch M. Intussusception in early childhood: a cohort study of 1.7 million children. Pediatrics. 2004; 114:782-5.

15 Stature-for-age charts for both gender developed by National Centre for Health Statistics in collaboration with the National Center for Chronic Disease Prevention and Health Promotion (2000).website:www.cdc.gov/growthcharts/data/set2clinical/cj41c071.pdf.

16 Stringer MD, Pablot SM, Brereton RJ. Paediatric intussusception. Br J Surg. 1992; 79:86.

17 Yalcin S. Presenting clinical features and outcome in intussusception, Indian J Pediatr. 2009; 76(4):401-5.

18 Weihmiller. Risk stratification of children being evaluated for intussusception. Pediatrics. 2011; 127(2):296303.

19 Bajaj. Post reduction Management of intussusception in a children's Hospital Emergency Department. Pediatrics. 2003; 112(6):1302-7.

20 Khan J. Retrospective analysis of clinical presentation of children with diagnosed intussusception. JPM. 2007; 21(2):151-3. 
21 Krishna Kumar. Ultrasound guided hydrostatic reduction in the management of intussusception. Indian J Pediatr. 2006; 73(3):217-21.

22 Julie EB, Nguyen TL, Frances J, Tran NS, John BC, Margaret DC, et al. Validation of clinical case definition of acute intussusception in infants in Viet Nam and Australia. Bull World Health Organ, 2006; 84:1-11.

23 Hutchison IF, Olayiwola B, Young DG. Intussusception in infancy and childhood. Br J Surg. 1980; 67:209-12.

24 Ein SH, Stephen CA. Intussusception 354 cases in 10 years. J Pediatr Surg. 1971; 6:16-27.

25 Justice FA, Auldist AW, Bines JE. Intussuscepion: trends in clinical presentation and man-agement. J Gastroenterol Hepatol. 2006; 21(5):842-6.

26 Pisacane A, Caracciolo G, de Luca U. Infant feeding and idiopathic intussusception. J Pediatr. 1993; 123(4):593-5.

27 Chang HG, Smith PF, Ackelsberg J, Morse DL, Glass RI. Intussusception, rotavirus diarrhea, and rotavirus vaccine use among children in New York State. Pediatrics. 2001; 108(1):54-60.

28 Zanardi LR, Haber P, Mootrey GT, Niu MT, Wharton M. VAERS Working Group. Intussusception among recipients of rotavirus vaccine: reports to the vaccine adverse event reportingsystem.Pediatrics.2001; 107(6).Availableat:http://www.pediatrics.org/cgi/content/full/107/ 6/e97.

29 Klein EJ, Kapoor D, Shugerman RP. The diagnosis of intussusception. Clin Pediatr (Phila). 2004; 43(4):34334.

30 Daneman A, Alton DJ, Lobo E, Gravett J, Kim P, Ein SH. Patterns of recurrence of intussusception in children: a 17 year review. Pediatr Radiol. 1998; 28(12):913-9. 